\title{
A hospital based retrospective study of thyroid disorders on obstetric and perinatal outcomes
}

\author{
Sagar R. Patel*, Pushpa A. Yadava, Shital T. Mehta, Bina M. Raval, \\ Viditsinh P. Sisodiya, Riya A. Parikh, Mital R. Viraja
}

Department of Obstetrics and Gynaecology, Smt. NHL Municipal Medical College, SVPIMSR, Ahmedabad, Gujarat, India

Received: 30 August 2020

Accepted: 06 October 2020

*Correspondence:

Dr. Sagar R. Patel,

E-mail: psagar1994@yahoo.in

Copyright: (C) the author(s), publisher and licensee Medip Academy. This is an open-access article distributed under the terms of the Creative Commons Attribution Non-Commercial License, which permits unrestricted non-commercial use, distribution, and reproduction in any medium, provided the original work is properly cited.

\section{ABSTRACT}

Background: The study was undertaken in pregnant women to understand and analyze the obstetric and foetal outcomes of thyroid disorders.

Methods: TSH estimation was used as universal screening in their first visit to our hospital. Those patients with abnormal TSH values, i.e. above $2.5 \mathrm{mIU} / \mathrm{ml}$ in first trimester and above $3 \mathrm{mIU} / \mathrm{ml}$ in second and third trimesters were evaluated for free T3, free T4 and TPO Abs. They were treated accordingly and dosage adjustments made and the tests repeated once in 4-6 weeks. They were followed throughout pregnancy and delivery.

Results: Total no of pregnant women screened were 904 over a period of 1 year from 15 March 2019 to 14 March 2020, of which 115 had abnormal thyroid functions, thereby the prevalence of thyroid disorders being $12.72 \%$. Of the 115 patients with thyroid disorders, 112 were hypothyroid and 3 were hyperthyroid. Among the 112 hypothyroid cases, 48 were known cases and 64 were new cases. The total cases of subclinical hypothyroidism were 88 , prevalence being $9.73 \%$ and overt cases were 24 , prevalence being $2.65 \%$; 3 cases were overt hyperthyroid, prevalence being $0.33 \%$. $66 \%$ of subclinical hypothyroidism were TPO positive and $34 \%$ of overt hypothyroidism were TPO positive $(\mathrm{p}<0.05)$. Out of 115 abnormal thyroid function patients, 92 patients delivered in our hospital. There were 15 abortions, 13 spontaneous and 2 terminations of pregnancies; 7 patients have delivered outside and 1 patient lost follow up.

Conclusions: The prevalence of thyroid disorders during pregnancy was significantly more in our study, hypothyroidism being the commonest. Significant numbers of cases were newly diagnosed on universal screening. The commonest disorder was subclinical hypothyroidism. Adverse maternal and foetal outcomes were almost similar in both subclinical and overt hypothyroidism. The common adverse outcomes noted were abortions, pre-eclampsia, gestational diabetes mellitus, preterm births and increased rates of caesarean sections. The adverse outcomes were significantly more in autoimmune antibody positive patients.

Keywords: Sub-clinical hypothyroidism, Overt hypothyroidism, Thyro-peroxidase antibody, Hyperthyroidism

\section{INTRODUCTION}

The thyroid gland is a small endocrine organ located in front of the trachea which utilizes iodine to produce thyroid hormones, which are essential for normal growth, development, maturation and regulation of metabolism.
Thyroid dysfunction during pregnancy had been an important research area in clinical endocrinology due to the fact that thyroid dysfunction has immense impact on maternal and foetal outcomes. ${ }^{1,2}$

Thyroid diseases are known to affect the reproductive health of women, who thus have trouble in conceiving or 
have more miscarriages. ${ }^{3,4}$ Thyroid disease varies from $2.5 \%$ from the West to $11 \%$ from India. ${ }^{5,6}$ Thyroid dysfunction is associated with foetal loss, foetal growth restriction, placental abruptions, pre-eclampsia, preterm delivery and reduced intellectual function in the offspring.

The foetus is totally dependent on maternal thyroid hormone supply during the first trimester of pregnancy, which is the important time in organogenesis. ${ }^{7}$ So the key is to correctly identify these disorders and appropriately treat them to prevent pregnancy related complications and to ensure delivery of a healthy baby. Clinical or subclinical thyroid disorders are usually detected during pre-conceptional counselling or in women who have just conceived and have done tests for thyroid function. The TSH test is usually proposed as the initial test in screening because of its ability to detect abnormalities before serum T4 and T3 levels are abnormal. The most frequent thyroid disorder in pregnancy is maternal hypothyroidism.

\section{Objectives of the study}

Objectives of current study were, to assess the thyroid status and prevalence of thyroid diseases in pregnancy, to study the pregnancy outcome of affected pregnancies and to know the type of thyroid disorders in these subjects.

\section{METHODS}

\section{Source of data}

Data was collected from department of obstetrics and gynecology, Sardar Vallabhbhai Patel hospital, Ahmedabad.

\section{Study population}

Study population in current study were pregnant women in any trimester of pregnancy who attended the outpatient department, inpatient department and the labour ward of OBG, over a period of one year were selected for the study and were followed up till delivery and the perinatal period.

\section{Inclusion criteria}

Inclusion criteria for current study were; all pregnant women with single intra uterine gestation belonging to any trimester of pregnancy who reported to the obstetric department of SVP were studied and pregnant women with established thyroid dysfunction with or without treatment in any trimester of pregnancy were also studied for obstetric and perinatal outcome.

\section{Exclusion criteria}

Exclusion criteria for current study were; patients who are on drugs affecting thyroid function like lithium, iodine, and amiodarone and patients who have undergone thyroid surgery. •

Complete history was taken and detailed examination was performed on the patient according to the proforma. Informed consent to participate in this study was taken. Serum samples were collected for TSH estimation by chemiluminescence immunoassay technique in our laboratory. When TSH was abnormal, free T4, free T3 and anti TPO antibodies were estimated. Women diagnosed with abnormal hormone levels were referred to endocrinology clinic of our institution for a simultaneous treatment and follow up. Routine antepartum management was done and women were followed till delivery and perinatal period.

Maternal outcome variables included the occurrence of abortions, pre-eclampsia, gestational diabetes mellitus and obstetric complications like abruptio placenta, overall rate of caesarean sections, assisted vaginal delivery. Perinatal outcome variables included the incidence of LBW, prematurity, IUGR, foetal demise and congenital hypothyroidism.

Normal readings of hospital laboratory standards were, TSH values; first trimester, 0.1-2.5 $\mathrm{mIU} / \mathrm{ml}$, second trimester, $0.2-3.0 \mathrm{mIU} / \mathrm{ml}$, third trimester, 0.3-3.0 $\mathrm{mIU} / \mathrm{ml}$, free T3 values, $2.0-3.8 \mathrm{pg} / \mathrm{ml}$ and free T4 values, $0.72-2.24 \mathrm{ng} / \mathrm{dl}$.

\section{Statistical methods}

The information collected regarding all the selected cases were recorded in a master chart. Data analysis was done with the help of a computer using Sigmastat software. Chi square test was used to analyze the differences between the proportions (comparative groups), wherever applicable. $\mathrm{p}<0.05$ was considered for significant relationship. Interpretation of $\mathrm{p}$ value was; suggestive significance, $0.05<\mathrm{p}<0.10$, moderately significant, $0.01<$ $\mathrm{p}<0.05$, strongly significant, $\mathrm{p}<0.01$.

\section{RESULTS}

In this study, a total of 904 pregnant patients were screened for the thyroid functions. Out of the 904 pregnant patients, 115 of them had abnormal thyroid functions. Prevalence of thyroid disorders during pregnancy $12.72 \%$. The mean age of the patients screened was 26.9 years.

Out of the 115 cases, 42 were primigravidae and the remaining 73 were multigravidae. Among the multigravidae, 40 were second gravidae, 28 were third gravidae and remaining 05 were higher order gravidae.

At the beginning of the study, 49 cases (only 42.6\%) were known cases of thyroid dysfunction, of which known cases of hypothyroidism were $48(41.74 \%)$ and known cases of hyperthyroidism were $01(0.87 \%)$ cases. 
The remaining 66 cases $(57.4 \%)$ were newly diagnosed during screening. Of the 66 new cases, 64 were hypothyroidism $(55.7 \%)$ and 2 were hyperthyroidism cases $(1.7 \%)$.

Table 1: Distribution of thyroid cases.

\begin{tabular}{|lll|}
\hline & Frequency & Percentage \\
\hline Known hypothyroid & 48 & 41.7 \\
\hline Known hyperthyroid & 01 & 0.9 \\
\hline New hypothyroid & 64 & 55.7 \\
\hline New hyperthyroid & 02 & 1.7 \\
\hline Total & 115 & 100 \\
\hline
\end{tabular}

Table 2: Distribution of hypothyroid and hyperthyroid cases.

\begin{tabular}{|lll|}
\hline & Frequency & Percentage \\
\hline Subclinical hypothyroid & 88 & 76.5 \\
\hline Overt hypothyroid & 24 & 20.9 \\
\hline Overt hyperthyroid & 03 & 2.6 \\
\hline Total & 115 & 100 \\
\hline
\end{tabular}

Out of the 112 hypothyroid cases, 88 cases $(78.57 \%)$ were subclinical hypothyroidism and 24 (21.43\%) were overt hypothyroidism cases. Of the 3 hyperthyroid cases, all were overt hyperthyroidism cases and there were no subclinical hyperthyroid cases.
Table 3: Distribution of TPO positive and negative cases.

\begin{tabular}{|lll|}
\hline & Frequency & Percentage \\
\hline TPO negative & 65 & 58 \\
\hline TPO positive & 47 & 42 \\
\hline Total & 112 & 100 \\
\hline
\end{tabular}

Out of the 112 hypothyroid cases, 47 cases (42\%) were TPO positive and $65(58 \%)$ were TPO negative. Out of the 47 TPO positive cases, 31 cases (66\%) were subclinical (euthyroid) TPO positive cases and 16 cases (34\%) were overt TPO positive cases. Of the 65 TPO negative cases, 57 cases were subclinical cases and 08 cases were overt cases. So, TPO positivity among subclinical hypothyroidism, 66\% and TPO positivity among overt hypothyroidism $34 \%$.

Out of the total 115 cases of thyroid disorders, there were 15 abortions. Of the remaining 100 cases, 92 patients delivered in our hospital, 1patients were lost for follow up, and 7 patients have delivered outside.

The foetal outcomes in the 92 cases were as follows, there were 71 normal foetuses and 21 abnormal foetuses. Abnormal foetuses included preterm, IUGR, LBW and IUD babies. Among the 21 abnormal foetuses, 13 were preterm, 2 were IUDs and the remaining 6 included IUGR, LBW and SGA babies. The correlation between diagnosis and foetal outcome is mentioned in (Table 4).

Table 4: Foetal outcomes in thyroid disorders, diagnosis foetus cross tabulation.

\begin{tabular}{|lllll|}
\hline \multirow{2}{*}{ Count } & & Foetus & & Tbnormal \\
& & Normal & Abotal \\
\hline \multirow{3}{*}{ Diagnosis } & Sub-clinical hypothyroid & 55 & 11 & 66 \\
& Overt hypothyroid & 15 & 09 & 24 \\
\cline { 2 - 6 } & Overt hyperthyroid & 02 & 00 & 02 \\
\hline Total & & 71 & 21 & 92 \\
\hline
\end{tabular}

Table 5: Foetal outcomes in TPO positivity.

\begin{tabular}{|c|c|c|c|c|}
\hline \multirow{2}{*}{\multicolumn{2}{|c|}{$\begin{array}{l}\text { TPO abs foetus cross tabulation } \\
\text { count }\end{array}$}} & \multicolumn{2}{|l|}{ Foetus } & \multirow{2}{*}{ Total } \\
\hline & & Normal & Abnormal & \\
\hline \multirow{2}{*}{ TPO abs } & TPO negative & 56 & 03 & 59 \\
\hline & TPO positive & 15 & 18 & 33 \\
\hline \multicolumn{2}{|l|}{ Total } & 71 & 21 & 92 \\
\hline
\end{tabular}

The observed Chi square value was 5.058 and $\mathrm{p}<0.05$, so the association between thyroid disorders and abnormal fetal outcome was statistically significant. The association between TPO antibodies and fetal outcomeis mentioned in (Table 5). The observed Chi square value was 29.39 and $p<0.05$, so the association between TPO positivity and abnormal fetal outcome was statistically significant.
The adverse obstetric and perinatal outcomes associated with thyroid disorders during pregnancy showed that there was overlapping of complications like preeclampsia, GDM, preterm births, IUGR and abruption in some cases. In our study, there were 15 abortions (13\%). 13 were spontaneous and 2 were terminated in view of high TSH levels $(>150 \mathrm{mIU} / \mathrm{ml})$ and strong TPO positivity ( $>1500)$. Out of the 15 abortions, 13 were in 
TPO positive cases and only 1 in TPO negative case. One abortion was seen in hyperthyroidism. Prevalence of abortions in thyroid dysfunction was observed as $13 \%$. Prevalence of abortions in TPO positive cases was $27.65 \%$.

There were 19 cases of pre-eclampsia, 15 in TPO positive patients, 3 in TPO negative cases and 1 in hyperthyroid patients. Prevalence of pre-eclampsia in thyroid dysfunction was found to be $16.52 \%$. Prevalence of preeclampsia in TPO positive cases was $32 \%$. There were 10 cases of GDM, 6 in TPO positive, 4 in TPO negative and 0 in hyperthyroidism. Prevalence of GDM in thyroid dysfunction was $8.69 \%$. Prevalence of GDM in TPO positive cases was $12.76 \%$. There were 6 cases that had both pre-eclampsia and GDM and among them, 5 were in TPO positive and 1 was in hyperthyroidism. Prevalence of pre-eclampsia and GDM in TPO positive cases was found to be $10.63 \%$. No case of congenital hypothyroidism was seen among the babies.

Table 6: Obstetric and perinatal outcomes in thyroid disorders complications.

\begin{tabular}{|lll|}
\hline Complications & Hypothyroidism & Hyperthyroidism \\
\hline Abortion & 14 & 01 \\
\hline Pre-eclampsia & 18 & 01 \\
\hline GDM & 10 & 00 \\
\hline $\begin{array}{l}\text { Pre-eclampsia } \\
\text { + GDM }\end{array}$ & 05 & 01 \\
\hline PPROM & 04 & 00 \\
\hline Pre term birth & 13 & 00 \\
\hline IUGR/LBW & 06 & 00 \\
\hline Abruption & 01 & 00 \\
\hline Stillbirth/IUD & 02 & 00 \\
\hline
\end{tabular}

\section{DISCUSSION}

This study was aimed to evaluate thyroid function in pregnant women and to find the pregnancy outcome in them. There has been a wide geographic variation in prevalence of hypothyroidism during pregnancy. It varies from $2.5 \%$ from the West to $11 \%$ from India. ${ }^{5,6}$

According to our study, the prevalence and pattern of thyroid disorders during pregnancy were; prevalence of thyroid dysfunction during pregnancy, $12.72 \%$, subclinical hypothyroidism, $09.73 \%$, overt hypothyroidism, $2.65 \%$ and hyperthyroidism, $0.33 \%$.

In current study, it was observed that the prevalence of thyroid disorders during pregnancy was significantly more. Hypothyroidism was more common than hyperthyroidism. Newly diagnosed cases of thyroid dysfunction by universal screening using TSH were significant in numbers, the commonest disorder being subclinical hypothyroidism.
The common adverse outcomes noted were abortions, pre-eclampsia, gestational diabetes mellitus, preterm births and increased rates of caesarean sections. The adverse outcomes were significantly more in autoimmune antibody positive patients.

Most of the western literature reveals that the prevalence of subclinical hypothyroidism is $2-2.5 \%$ and the prevalence of overt hypothyroidism is 2-3/1000 pregnant population. Another study examined 500 pregnant women attending two government obstetrics and gynecology hospitals in Chennai during a period of 5 months for thyroid function. Subclinical hypothyroidism was detected in 2.8\%, among them TPO antibodies positivity was seen in $57.1 \% .^{8}$ In a study from India, Nambiar et al have reported prevalence of hypothyroidism and thyroid autoimmunity as $4.8 \%$ and $12.4 \%$, respectively and were significantly associated with miscarriage. ${ }^{9}$ Vanderpump and Turnbridge reported a prevalence of $1-2 \%$ for overt hypothyroidism and $8 \%$ for subclinical hypothyroidism. ${ }^{10}$

The prevalence rates in our study were comparatively higher probably because our cut off values for TSH were gestational age specific, $0.12 .5 \mathrm{mIU} / \mathrm{ml}, 0.2-3.0 \mathrm{mIU} / \mathrm{ml}$, 0.3-3.0 $\mathrm{mIU} / \mathrm{ml}$ for first, second and third trimesters respectively. Also, in our study, those patients who were already known cases of thyroid disorders with or without treatment were also included whereas they were excluded in the study by Sahu et al. Non-pregnant TSH reference values are unreliable in pregnancy. The TSH reference value in our study was between 0.1-3.0 mIU/ml. This was adapted because it is supported by literature.

American thyroid association has stressed daily dosage of thyroxine should be adjusted to keep TSH at 1-2 mIU/ml. Truly normal range of TSH is defined as $0.52 .5 \mathrm{mIU} / \mathrm{ml}-$ William et al. ${ }^{11}$

Also in our study, we employed universal screening of thyroid dysfunction during pregnancy. Targeted case finding is recommended at the first prenatal visit or at diagnosis of pregnancy. Vaidya et al recently reported a study of screening by means of TSH, T4, free T4, and TPO-Ab in 1560 consecutive pregnant women. ${ }^{12}$

A large-scale double blind prospective study, entitled the "controlled antenatal thyroid screening study" has been initiated by Lazarus and associates. Serum samples are obtained before 16 week gestation, with half of the sera analyzed immediately for free T4 and TSH, and the other half frozen until delivery. Women with a free T4 below the 2.5th percentile and/or TSH above the 97.5th percentile receive levothyroxine therapy. The main outcome measure will be the development of the unborn child as measured at 3 year of age. Outcome data, when available, will be instrumental in beginning to develop a rational response to the screening controversy. 


\section{Prevalence of anti TPO antibodies}

In current study, the prevalence of anti TPO antibodies was, overall, TPO positivity among hypothyroid patients, $41.96 \%$, TPO positivity among subclinical hypothyroidism was $66 \%$, TPO positivity among overt hypothyroidism was $34 \%$. The overall rate of miscarriage is $13 \% \quad(p<0.05)$ in current study but the majority occurred in TPO positive cases. More than $27.7 \%$ abortions were in the TPO positive group.

LSCS rates $(54.34 \%)$ were higher in thyroid disorders because of associated complications like pre-eclampsia, gestational diabetes, IUGR, etc. The chi square value is 5.691 and so the $\mathrm{p}<0.05$ and so the association between thyroid disorders and abnormal foetal outcome is statistically significant.

\section{CONCLUSION}

Maternal thyroid dysfunction is a disorder with great potential to adversely affect maternal and fetal outcomes and is also associated with multiple other conditions which can affect maternal and fetal health. Thyroid disease in pregnancy is common, clinical important and time sensitive. This study concludes that thyroid disorders are common in pregnancy, and the most common disorder is subclinical hypothyroidism. There is a high prevalence of hypothyroidism (12.72\%) in pregnant women, majority being subclinical and have high rates of TPO antibody positivity. Screening for thyroid function and autoimmunity, and timely and appropriate treatment, will improve pregnancy outcome.

\section{Funding: No funding sources}

Conflict of interest: None declared

Ethical approval: The study was approved by the Institutional Ethics Committee

\section{REFERENCES}

1. Negro R, Schwartz A, Gismondi R, Tinelli A, Mangieri T, Stagnaro-Green A. Increased pregnancy loss rate in thyroid antibody negative women with TSH levels between 2.5 and 5.0 in the first trimester of pregnancy. J Clin Endocrinol Metab. 2010;95(9): E44-8.

2. Casey BM, Dashe JS, Wells CE, McIntire DD, Byrd W, Leveno KJ, et al. Subclinical hypothyroidism and pregnancy outcomes. Obstet Gynecol. 2005;105(2): 239-45.
3. Stagnaro-Green A, Roman SH, Cobin RH, Harazy E, Alvarez-Marfany M, Davies TF. Detection of at-risk pregnancy by means of highly sensitive assays for thyroid autoantibodies. JAMA. 1990;264(11):14225 .

4. Abalovich M, Gutierrez S, Alcaraz G, Maccallini G, Garcia A and Levalle O. Overt and subclinical hypothyroidism complicating pregnancy. Thyroid. 2002;12(1):63-8.

5. Stagnaro-Green A. Thyroid antibodies and miscarriage: Where are we at a generation later? J Thyroid Res. 2011;2011:841949.

6. Männistö T, Vääräsmäki M, Pouta $\mathrm{A}$, Hartikainen AL, Ruokonen A, Surcel HM, et al. Perinatal outcome of children born to mothers with thyroid dysfunction or antibodies: A prospective populationbased cohort study. J Clin Endocrinol Metab. 2009; 94:772-9.

7. Calvo RM, Jauniaux E, Gulbis B, Asuncion M, Gervy C, Contempre B, et al. Fetal tissues are exposed to biologically relevant free thyroxine concentrations during early phases of development. J Clin Endocrinol Metab. 2002;87(4):1768-77.

8. Gayathri R, Lavanya S, Raghavan K. Subclinical hypothyroidism and autoimmune thyroiditis in pregnancy - a study in South Indian subjects. J Assoc Physicians India. 2009;57:691-3.

9. Nambiar V, Jagtap VS, Sarathi V, Lila AR, Kamalanathan S, Bandgar TR, et al. Prevalence and impact of thyroid disorders on maternal outcome in Asian-Indian pregnant women. J Thyroid Res. 2011; 2011:429097.

10. Vanderpump MP, Tunbridge WM, French JM, Appleton D, Bates D, Clark F, et al. The incidence of thyroid disorders in the community: a twenty-year follow-up of the Whickham Survey. Clin Endocrinol (Oxf). 1995;43(1):55-68.

11. Hypothyroid patients should be assessed regularly. Therapeutics Today 2005;9:1-2.

12. Vaidya B, Anthony S, Bilous M, Shields B, Drury J, Hutchison $S$, et al. Detection of thyroid dysfunction in early pregnancy: Universal screening or targeted high-risk case finding?. J Clin Endocrinol Metab. 2007;92(1):203-7.

Cite this article as: Patel SR, Yadava PA, Mehta ST, Raval BM, Sisodiya VP, Parikh RA, et al. A hospital based retrospective study of thyroid disorders on obstetric and perinatal outcomes. Int J Reprod Contracept Obstet Gynecol 2020;9:4590-4. 